\title{
Bandwidth Improvement of Dual Band Printed Rectangular Monopole Antenna
}

\author{
Vijayalakshmi Hunnur ${ }^{1}$, Akanksha Agrawal ${ }^{2}$, Darpan Savla ${ }^{3}$, Mahima Kaul ${ }^{4}$, Jyoti Kori ${ }^{5}$ \\ Student, Department of Electronics, Thakur College of Engineering \& Technology, Mumbai, India ${ }^{1,2,3,4}$ \\ Assistant Professor, Department of Electronics, Thakur College of Engineering \& Technology, Mumbai, India ${ }^{5}$
}

\begin{abstract}
This paper describes the design of the printed rectangular monopole antenna using inset field in rectangular shape operating at $2.4 \mathrm{GHz}$. The dimensions of each single element of the planar monopole antenna at the operating frequency are calculated using transmission line model. Broadband planar monopole antennas have all the advantages of the monopole in terms of their cost, and ease of fabrication besides, yielding very large bandwidths. For many applications large bandwidth is required. Recently, many techniques to tailor and optimize the impedance BW of these antennas have been investigated. These antennas are becoming popular, and have been proposed for modern and future wideband wireless applications. The radiation performance is also shown to be acceptable over a wide range of frequency. Optimization of the feed point location can achieve very compact configurations. Also these antennas can provide band-notching characteristics. These antennas have been reported to provide multi band characteristics too. More recently, it has been shown that, although the square monopole (SM) provides smaller BW than the circular monopole (CM), its radiation pattern suffers less degradation within the impedance BW.
\end{abstract}

Keywords: Printed Rectangular Monopole antenna, antenna feeds, Slot cut, offset feed and broadband antenna.

\section{INTRODUCTION}

Today's world demands antennas that are diminutive but provide a wide impedance bandwidth for greater number of applications. Planar monopole antenna sees its applications in many wireless communication services because of its wide impedance bandwidth, compact simple structure and ease of fabrication [1-7]. A printed configuration of the rectangular monopole antenna has been reported along with its parametric studies. The main purpose of this paper was to optimize the bandwidth of the Rectangular printed monopole antennas (PRMA). The geometrical configurations of PRMA were varied to obtain a higher bandwidth for wide-band applications.

Previously reported printed rectangular monopole antenna [1-3] have given detailed study of all regular geometries of printed monopole antenna (PMA) with various feed positions and its effect on impedance bandwidth. The effect of feed configuration is also a critical parameter in determining the performance of the PMA. The feed was offsetted and varied of the rectangular monopole antenna and also of the modified geometry to achieve VSWR $<=2$ which is in good agreement with the experimental results. The optimized configuration of PRMA gives the bandwidth of $6.6 \mathrm{GHz}$ for VSWR $<=2$.

This band is very useful for many wireless applications, which includes GSM1900, WCDMA (1.92 to $2.17 \mathrm{GHz}$ ), ISM band (2.4 to $2.4853 \mathrm{GHz})$, Wi-Fi band (2.4, 3.5 and 5 $\mathrm{GHz})[10,11]$.

\section{GEOMETRY OF PROPOSED PRINTED RECTANGULAR MONOPOLE ANTENNA}

A rectangular monopole antenna of size $50 \mathrm{~mm} X 40 \mathrm{~mm}$ was fabricated on a glass epoxy (FR4) substrate of $70 \mathrm{~mm}$ $\mathrm{X} 70 \mathrm{~mm}$ with thickness $=1.59 \mathrm{~mm}$, dielectric constant $=$ 4.3 and loss tangent $\tan \delta=0.01$. The ground plane is of size $70 \mathrm{~mm}$ X $10 \mathrm{~mm}$. The feed point's widths were

simulated for $0.5 \mathrm{~mm}, 1 \mathrm{~mm}$ and $2 \mathrm{~mm}$ and the optimized width was accepted for $1 \mathrm{~mm}$ wide [2]. The antenna is fed using $50-\mathrm{Ohm}$ micro strip line of $3 \mathrm{~mm}$ length above the ground plane [3]. The effect of ground plane length is negligible on bandwidth, so it was reduced from $20 \mathrm{~mm}$ to $10 \mathrm{~mm}[10,11]$. Therefore length of ground plane is fixed at $10 \mathrm{~mm}$ for reduced size of the substrate. The PRMA is simulated by using IE3D software[8,9] for various feed position with offsets $(0 \mathrm{~mm}$ to $8 \mathrm{~mm})$ and slot lengths $(4 \mathrm{~mm}$ to $12 \mathrm{~mm}$ ) and it's effect on bandwidth is studied.

The following sets of formulas are used to obtain the value of:

(1) Length (L) of the antenna

(2) Width (W) of the antenna

(3) $\varepsilon r e f f$

With the known data as:

$\mathrm{c}=3 * 10^{\wedge} 8 \mathrm{~m} / \mathrm{sec}$

$\varepsilon=2.2$

fo $=2.4 \mathrm{GHz}$

$\mathrm{h}=1.58 \mathrm{~mm}$

$$
\text { fo }=\frac{c}{2 \sqrt{\varepsilon_{\text {reff }}}}\left[\left(\frac{m}{\mathrm{~L}}\right)^{2}+\left(\frac{\mathrm{n}}{\mathrm{W}}\right)^{2}\right]^{\frac{1}{2}}
$$

Where $\mathrm{m}$ and $\mathrm{n}$ are modes along $\mathrm{L}$ and $\mathrm{W}$ respectively. For efficient radiation, the width $\mathrm{W}$ is given by Bahl and Bhartia as:

$$
\mathrm{W}=\frac{\mathbf{c}}{2 \mathbf{f o} \sqrt{\frac{\left(\varepsilon_{\mathbf{r}}+1\right)}{2}}}
$$

We get $\mathrm{W}=40.15$

The effective length of the patch Leff now becomes:

$$
\text { Leff }=\mathrm{L}+2 \Delta \mathrm{L}
$$

For a given resonance frequency fc, the effective length is given by: 


$$
\mathrm{L}=\frac{\mathrm{c}}{2 \mathrm{fo} \sqrt{\varepsilon_{\mathrm{reff}}}}
$$

Leff $=40.34 \mathrm{~mm} \mathrm{~L}=50 \mathrm{~mm}$.

From the above-calculated values, the rectangular monopole antenna was designed. The proposed printed rectangular monopole antenna is shown in figures 2,3 and 4. The feed point position is fixed at $6 \mathrm{~mm}$ on the right of the center. The effect of feed point variation is the same on either side of the center. The lower cut-off frequency at distance of $6 \mathrm{~mm}$ of the feed point is $3.68702 \mathrm{GHz}$.

After fabrication of this antenna, a SMA connector 7855 FEMALE is connected between the feed point of the antenna and the ground patch of the antenna. This ensures the connection of the feed circuit with the conductor.

Since the antenna fabricated is a dual band antenna, two different frequency bands are obtained; one for the lower frequency and one for the higher frequency, for VSWR $=2$. Rather than centre resonance frequency, lower edge frequency is calculated for planar monopole antenna [10]. The lower band edge frequency of planar monopole antennas for VSWR $=2$ is obtained by equating the area of the PRMA with that of its equivalent cylindrical monopole antenna of same height $\mathrm{L}$ and equivalent radius $\mathrm{r}$ [10] and is as given below:

$$
2 \pi \mathrm{rL}=\mathrm{WL}
$$

Which gives,

$$
r=\mathrm{W} / 2 \pi
$$

The input impedance of a $\lambda / 4$ monopole antennas is half of that of the $\lambda / 2$ dipole antenna. Thus, the input impedance of an infinitesimally thin monopole antenna is $36.5+\mathrm{j} 21.25 \Omega$, which is inductive. The real input impedance is obtained when a slightly smaller length of the monopole is used as given by:

$$
\mathrm{L}=0.24 \lambda \mathrm{F}
$$

Where

$$
\mathrm{F}=(\mathrm{L} / \mathrm{r}) /(1+\mathrm{L} / \mathrm{r})=\mathrm{L} /(\mathrm{L}+\mathrm{r})
$$

From (3) and (4), the wavelength $\lambda$ is obtained as

$$
\lambda=(\mathrm{L}+\mathrm{r}) / 0.24
$$

Therefore, the lower frequency $\mathrm{f}_{\mathrm{L}}$ is given by

$$
\mathrm{f}_{\mathrm{L}}=\mathrm{c} / \lambda=7.2 /(\mathrm{L}+\mathrm{r}) \mathrm{GHz}
$$

Equation (6) does not account for the effect of the probe length $\mathrm{p}$, which increases the total length of the antenna thereby reducing the frequency. Accordingly, this equation is modified to

$$
\mathrm{f}_{\mathrm{L}}=7.2 /(\mathrm{L}+\mathrm{r}+\mathrm{p}) \mathrm{GHz}
$$

Where $\mathrm{L}, \mathrm{r}$ and pare in centimetres. But the monopole is fabricated on a substrate, thus

$$
\mathrm{f}_{\mathrm{L}}=7.2 /(\mathrm{L}+\mathrm{r}+\mathrm{p}) \mathrm{k} \quad \mathrm{GHz}
$$

Where $\mathrm{k}$ is the correction factor, $\mathrm{k}=1.15$ for FR4 substrate with $\varepsilon_{\mathrm{r}}=4.3$ and $\mathrm{h}=0.159 \mathrm{~cm} \mathrm{[1-3]}$.

\section{PARAMETRIC STUDY AND RESULTS}

Printed Monopole Antennas are designed keeping in mind a lot of parameters that will affect the performance characteristics of the antenna. There are many parameters, which play a vital role in measurement of the performance of the antenna functioning and thereby help in proper measurement of its performance. The radiation pattern, VSWR curve, Smith chart and Impedance circle were observed and compared for all values. The PRMA is first set to a particular value of $\mathrm{L}$ and $\mathrm{W}$ that is derived from the formulas mentioned above. The following parameters were varied to obtain an antenna with optimized values.

\section{A. Offset Feed}

The For two different feed-point locations from the center of the antenna, variations in the input impedance Zin and VSWR with frequency millimetres are observed. With an increase in frequency, the input impedance moves in the clockwise direction in the Smith chart. VSWR graph was generated for the above design with different feed point positions and compared all the results of the PRMA and finally selected the best design amongst them keeping in mind the VSWR Graph formed. To display the effect of feed position on impedance bandwidth, corresponding VSWR plots are shown in figure 1. Hence, from the above comparison of various VSWR graphs, feed point was narrowed down to one at $6 \mathrm{~mm}$ from the center.

As the feed point was varied from the center to the right corner, VSWR value varied from VSWR $=1.989$ to $\mathrm{VSWR}=1.08$, which is close to the value of $\mathrm{VSWR} \leq 2$.

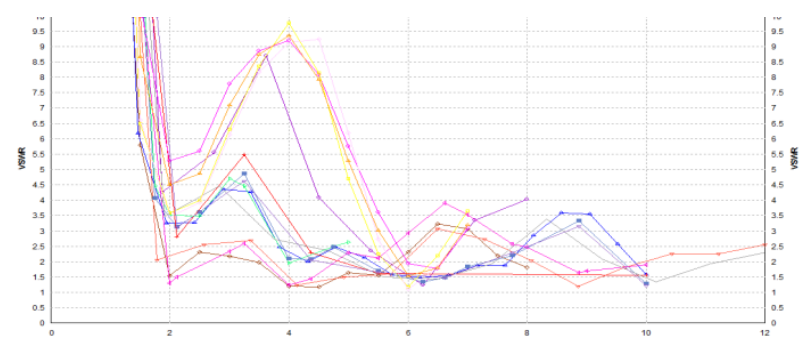

Fig.1. VSWR Graph at various feed point locations observed using IE3D software.

After locating the optimized feed point location using them Analyzer' to find the actual VSWR of the antenna.

B. Geometrical variation in PRMA

The geometrical variation or shape has great effects on the bandwidth of the antenna [10,11]. In this paper the shape of the PRMA is varied to measure the change in bandwidth. The conventional PRMA measuring $50 \mathrm{mmX} 40 \mathrm{~mm}$ is fabricated on the FR4 substrate as shown in figure 1.

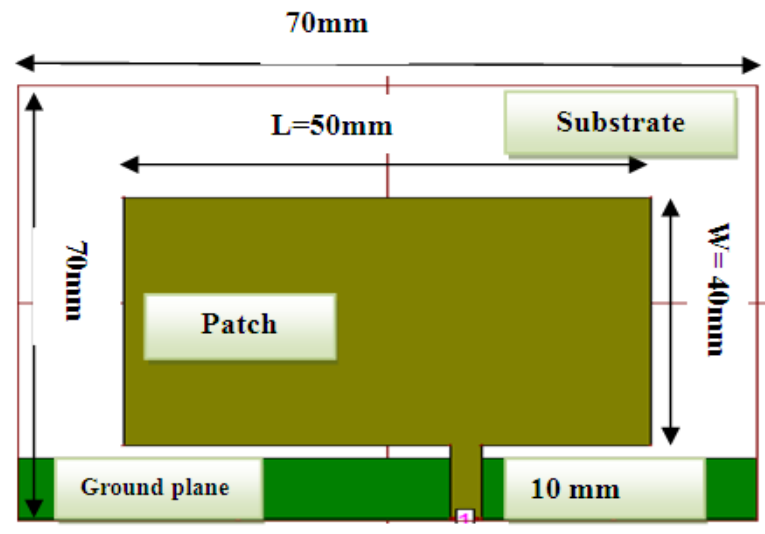

Fig.2. Geometry of Printed Rectangular Monopole Antenna 
Further, a slot in created at the center of the PRMA. Slot peak lies approximately close to desired set frequency width is kept constant at $4 \mathrm{~mm}$ and slot length is varied through our IE3D software. The 2 frequencies at which the from $4 \mathrm{~mm}$ to $12 \mathrm{~mm}$ as shown in figure 3. After varying antenna radiates maximum is $2.26 \mathrm{GHz}$ and $4.20 \mathrm{GHz}$. the values, the slot length was considered to be $9 \mathrm{~mm}$. The slot helps in reducing the return loss of the antenna and hence, achieving the optimum results.

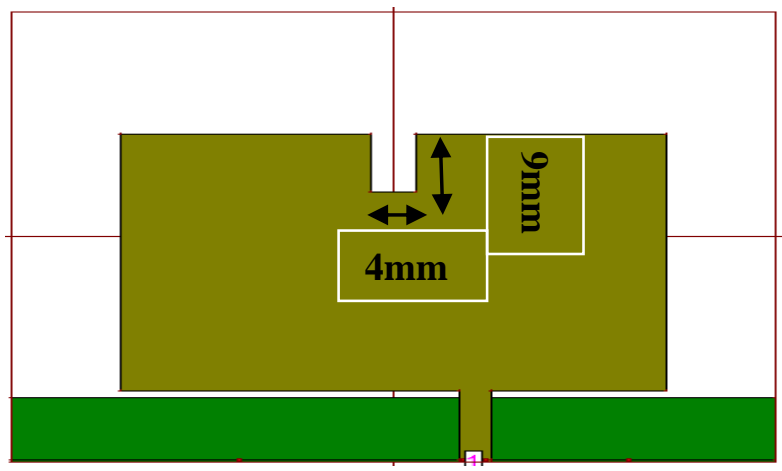

Fig. 3. Geometry of PRMA with slot at the center.

The geometry of the PRMA was further varied for increasing the bandwidth. The bottom left and right corners of the PRMA with the slot were rounded with a radius of $18 \mathrm{~mm}$ as in figure 4 .

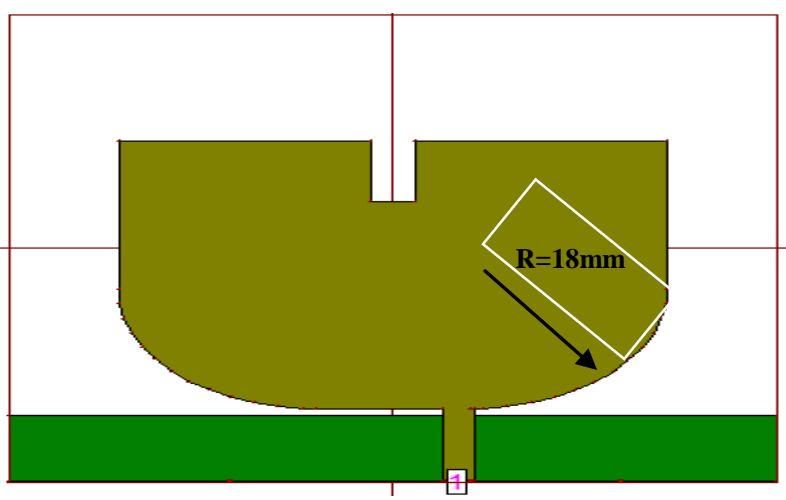

Fig. 4. Geometry of PRMA with slot at center and rounded base.

The bandwidth of the circular PRMA with slot and rounded base is in the range of $2 \mathrm{GHz}$ to $7 \mathrm{GHz}$ approximately.

(1) Printed Rectangular Monopole Antenna:

- VSWR:

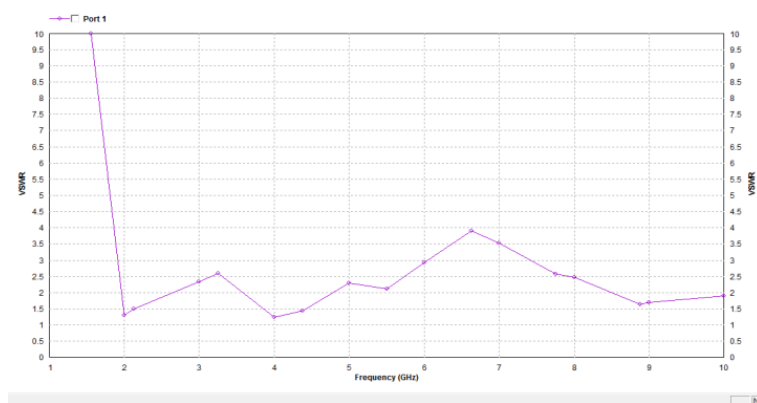

Fig.5. VSWR Graph at optimum feed point location using IE3D

The geometry of the PRMA after testing was found to be radiating at 2 values of frequency amongst which, the first
VSWR $=1.989$ and VSWR $=1.903$ respectively

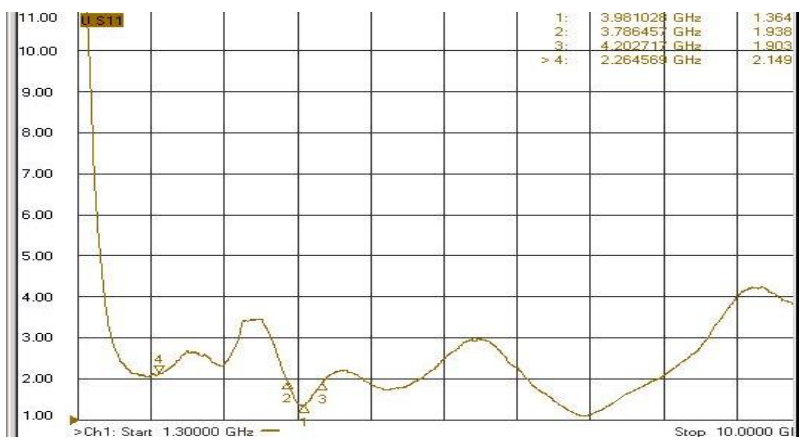

Fig.6. VSWR Graph obtained practically at optimum feed point location

- $\quad$ Return Loss:

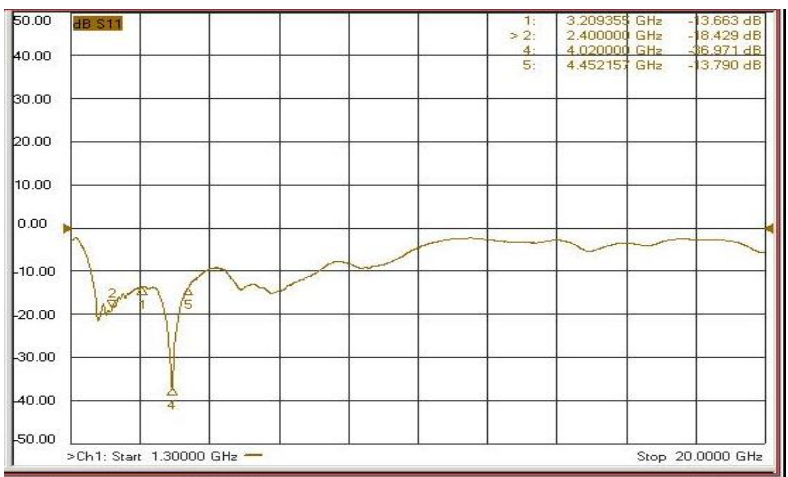

Fig.7. Return Loss Graph obtained practically at optimum feed point location

Return loss at $2.46 \mathrm{GHz}$ is $-17.35 \mathrm{~dB}$

Return loss at $4.20 \mathrm{GHz}$ is $-35.819 \mathrm{~dB}$

The return loss for the above geometry at the two bands is less than $-10 \mathrm{~dB}(-10 \mathrm{~dB}$ corresponds to a VSWR of 2 which is an acceptable figure)

$\bullet$

Smith Chart:

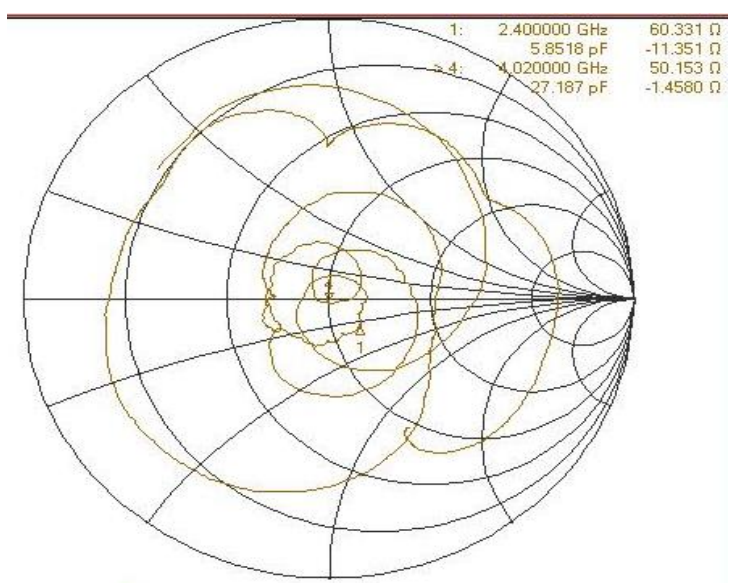

Fig.8. Smith Chart obtained practically at optimum feed point location

With the help of Smith Chart, the impedance of the antenna is calculated as: 
INTERNATIONAL JOURNAL OF INNOVATIVE RESEARCH IN ELECTRICAL, ELECTRONICS, INSTRUMENTATION AND CONTROL ENGINEERING Vol. 3, Issue 12, December 2015

At $2.26 \mathrm{Ghz}: 60.33-\mathrm{j} 11.351 \mathrm{ohms}$

At $4.20 \mathrm{GHz}: 50.153-\mathrm{j} 1.45 \mathrm{ohms}$.

(2) PRMA with slot:

- VSWR:

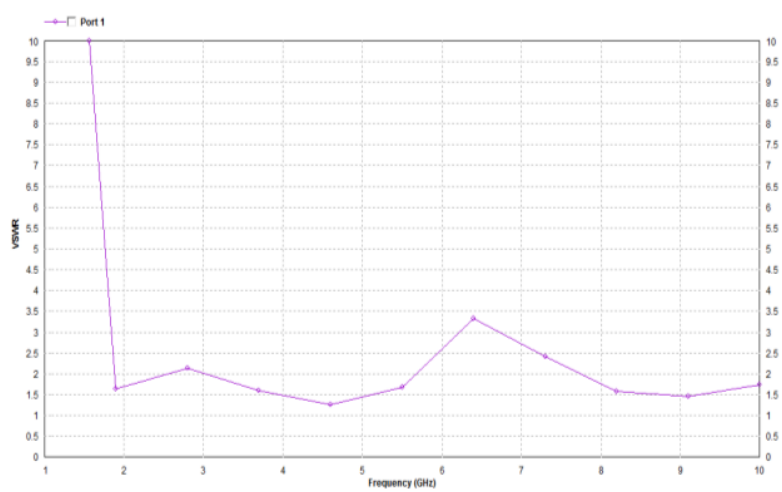

Fig.9. VSWR Graph at optimum feed point location using IE3D

The 2 frequencies at which the antenna radiates maximum is $2.79 \mathrm{GHz}$ and $4.14 \mathrm{GHz}$ and VSWR=1.765 and $\mathrm{VSWR}=1.349$.

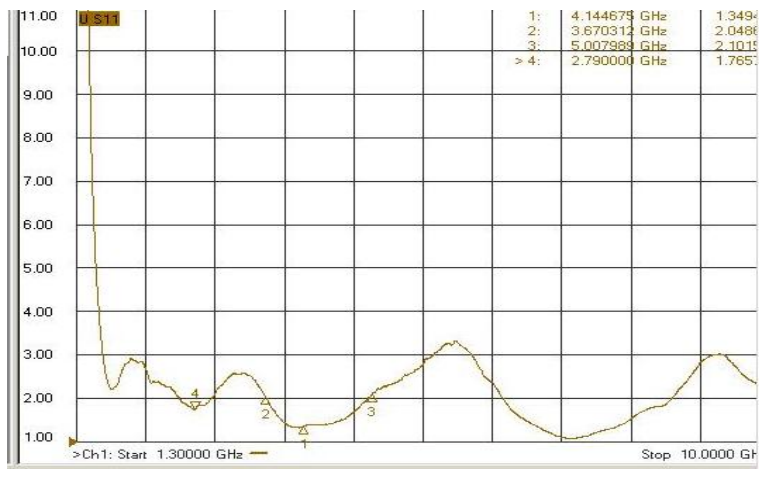

Fig.10.VSWR Graph obtained practically at optimum feed point

- Return Loss:

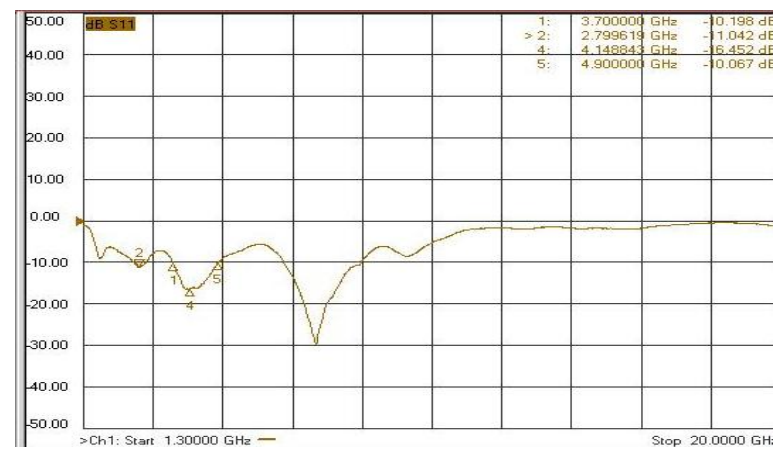

Fig.11. Return Loss obtained at optimum feed point location

Return loss at $2.79 \mathrm{GHz}$ is $-11.042 \mathrm{~dB}$

Return loss at $4.14 \mathrm{GHz}$ is $-16.452 \mathrm{~dB}$

- $\quad$ Smith Chart:

With the help of Smith Chart, the impedance of the antenna was calculated as:

$>$ At $2.79 \mathrm{Ghz}: 74.79-\mathrm{j} 25.9 \mathrm{ohms}$

$>$ At 4.14 Ghz: $64.3-\mathrm{j} 9.9$ ohms

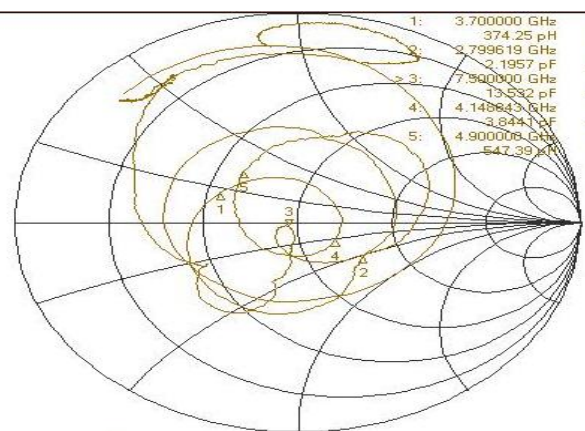

Stop $20.0000 \mathrm{GH}$

Fig.12. Smith Chart obtained practically at optimum feed point location

(3) PRMA with curved edges and slot:

- VSWR:

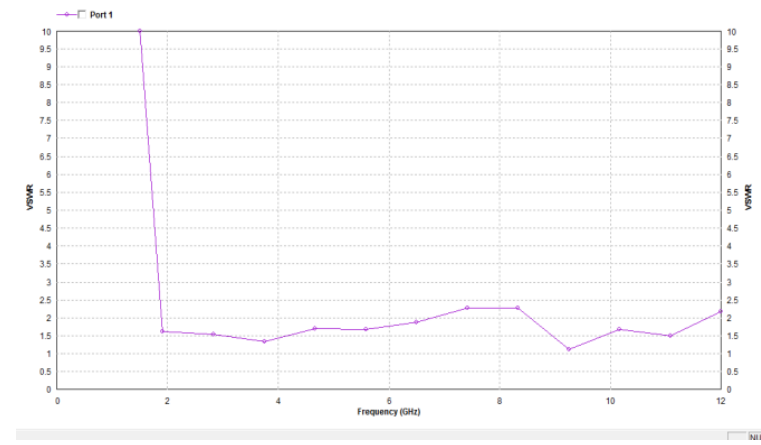

Fig.13. VSWR Graph at optimum feed point location using IE3D

The 2 frequencies at which our antenna radiates maximum are $2.4 \mathrm{GHz}$ and $4.02 \mathrm{GHz}$.

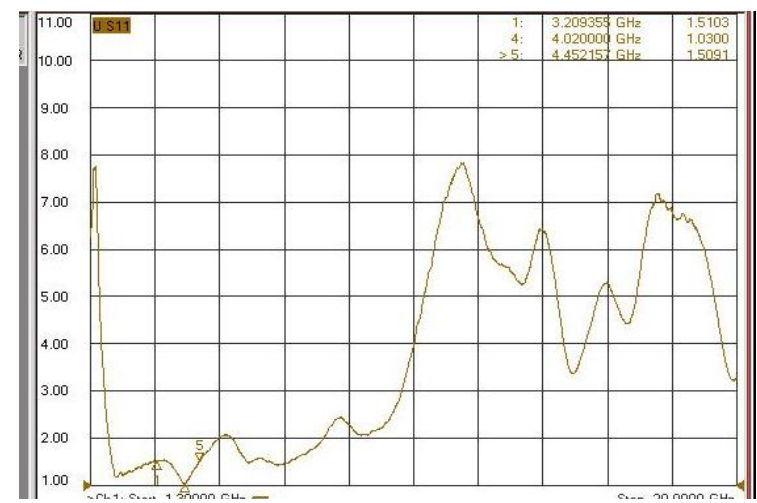

Fig.14. VSWR Graph obtained practically at optimum feed point

- $\quad$ Return Loss

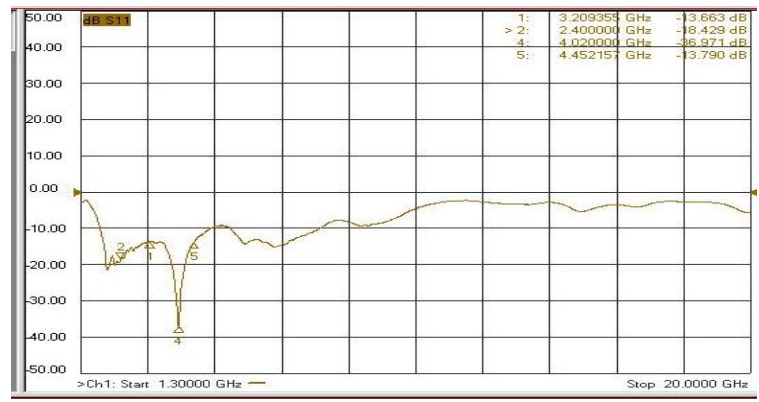

Fig.15. Return Loss obtained practically at optimum feed point 
INTERNATIONAL JOURNAL OF INNOVATIVE RESEARCH IN ELECTRICAL, ELECTRONICS, INSTRUMENTATION AND CONTROL ENGINEERING Vol. 3, Issue 12, December 2015

- Return loss at $2.4 \mathrm{GHz}$ is $-18.4 \mathrm{~dB}$

○ Return loss at $4.02 \mathrm{GHz}$ is $-35.97 \mathrm{~dB}$

Smith chart:

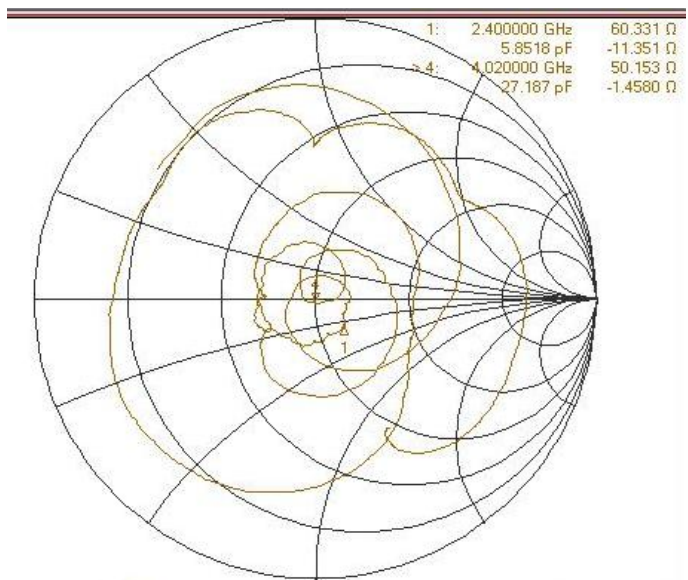

Fig.16. Smith Chart obtained practically at optimum feed point

With the help of Smith Chart, the impedance of the antenna can be calculated as:

○ At $2.4 \mathrm{Ghz}: 60.33-\mathrm{j} 11.35 \mathrm{ohms}$

○ At $4.02 \mathrm{Ghz}: 50.153$-j1.45 ohms

\section{COMPARISON OF PARAMETRIC EFFECTS}

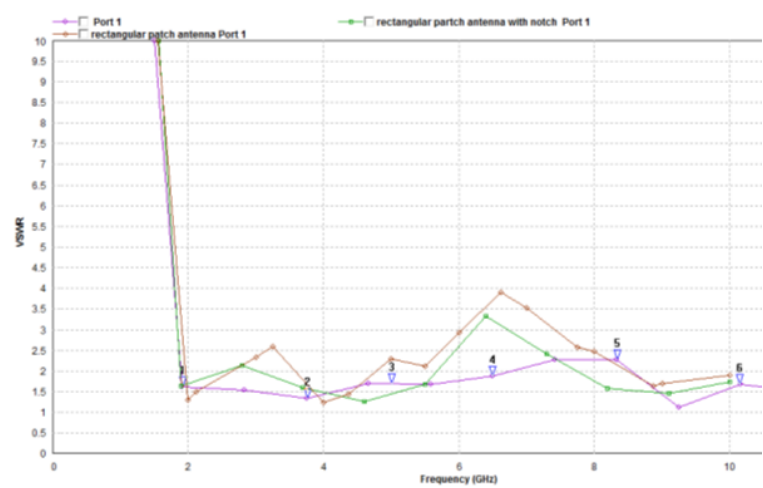

Fig.17. Shows graphical comparison of antennas results:

(a) Pink-PRMA with slot and curved base; (b) GreenPRMA with slot; (c) Red-PRMA.

The VSWR of the 3 PRMA designs are compared and tested using software IE3D and the Network Analyzer. It was observed that after testing of the 3 antenna designs, the frequency point at which at antennas were radiating were approximately of the same value as that of the frequency at which at the antenna was simulated through the software called Ie $3 \mathrm{~d}$ of Zealand.

A. Resonating Frequency

- Printed Rectangular Monopole antenna gives two bands as $2.26 \mathrm{GHz}(2.23 \mathrm{GHz}-2.27 \mathrm{GHz}), 4.20 \mathrm{GHz}($ $4.00 \mathrm{GHz}-4.25 \mathrm{GHz})$

- PRMA with slot gives two bands as $2.97 \mathrm{GHz}(2.95$ GHz- $3 \mathrm{GHz}), 4.14 \mathrm{GHz}(4.10 \mathrm{GHz}-4.15 \mathrm{GHz})$

- PRMA with rounded base edges gives two bands as 2.4 $\mathrm{GHz}(2.38 \mathrm{GHz}-2.42 \mathrm{GHz}), 4.02 \mathrm{GHz}(4.00 \mathrm{GHz}-$ $4.05 \mathrm{GHz})$
B. Return Loss

- From the table mentioned below it is concluded that the proposed geometry of circular PRMA gives better impedance matching indicated by return loss well below $-10 \mathrm{~dB}$

- It observed that as the width of the stub reduces, return loss can be minimized.

C.VSWR Plot

- VSWR for all the simulated range from 1.08 to 1.989 which is similar to the theoretical value less than 2 .

- VSWR value of the antenna should be near to 1 ,this results in no power reflected from the antenna which is the most ideal case desired.

D .Bandwidth

- Bandwidth for all the 3 configuration rage from $500 \mathrm{MHz}$ to $7 \mathrm{GHz}$.

- It was hence observed that the bandwidth has improved from PRMA design to PRMA with curved edges and slot design.

- The improvement in the bandwidth of the antenna design depicts its improvement in its performance and also maximizes its application.

E. Input Impedance

- Impedance relates the voltage and current at the input to the antenna.

- The real part of the antenna impedance represents power that is either radiated away or absorbed within the antenna. The imaginary part of the impedance represents power that is stored in the near field of the antenna. That is non-radiated power.

TABLE 1: COMPARISON OF PARAMETERS

\begin{tabular}{|c|c|c|c|c|c|}
\hline $\begin{array}{l}\text { Para } \\
\text { meter }\end{array}$ & $\begin{array}{l}\text { Frequen } \\
\text { cy }\end{array}$ & $\begin{array}{l}\text { VSW } \\
\text { R }\end{array}$ & $\begin{array}{l}\text { Retur } \\
\text { n loss }\end{array}$ & Impedance & BW \\
\hline \multirow{2}{*}{$\begin{array}{l}\text { PRM } \\
\text { A }\end{array}$} & $2.26 \mathrm{GHz}$ & 1.989 & $\begin{array}{c}- \\
8.7762\end{array}$ & $\begin{array}{c}94.252+\mathrm{j} 28 \\
.43\end{array}$ & \multirow{2}{*}{$\begin{array}{c}500 \\
\mathrm{MH} \\
\mathrm{z}\end{array}$} \\
\hline & $4.20 \mathrm{GHz}$ & 1.903 & $\begin{array}{c}- \\
10.092\end{array}$ & $\begin{array}{c}47.29- \\
j 31.812\end{array}$ & \\
\hline \multirow{2}{*}{$\begin{array}{l}\text { PRM } \\
\text { A with } \\
\text { slot }\end{array}$} & $2.97 \mathrm{GHz}$ & 1.765 & $\begin{array}{c}- \\
11.042\end{array}$ & $\begin{array}{c}74.79- \\
\text { j25.900 }\end{array}$ & \multirow{2}{*}{$\begin{array}{c}4.4 \\
\mathrm{GH} \\
\mathrm{z}\end{array}$} \\
\hline & $4.14 \mathrm{GHz}$ & 1.349 & $\begin{array}{c}- \\
16.452 \\
\end{array}$ & $\begin{array}{c}\text { 64.360- } \\
\text { j9.99 }\end{array}$ & \\
\hline \multirow{2}{*}{$\begin{array}{l}\text { PRM } \\
\text { A with } \\
\text { slot \& } \\
\text { round } \\
\text { ed } \\
\text { edges }\end{array}$} & $2.4 \mathrm{GHz}$ & 1.08 & $\begin{array}{c}- \\
17.351\end{array}$ & $\begin{array}{r}\text { 60.33- } \\
j 11.351\end{array}$ & \multirow{2}{*}{$\begin{array}{c}6.6 \\
\mathrm{GH} \\
\mathrm{z}\end{array}$} \\
\hline & $4.02 \mathrm{GHz}$ & 1.509 & $\begin{array}{c}- \\
35.819\end{array}$ & $\begin{array}{c}50.153- \\
\text { j1.45 }\end{array}$ & \\
\hline
\end{tabular}

\section{CONCLUSION}

The parametric study with variation states that with the shift of feed towards the edge, there is change in the VSWR and the impedance increases and shifts towards right. And hence, after comparison of different feed point locations, the optimum feed point location was obtained at $6.075 \mathrm{~mm}$ from the center of the antenna. The highest bandwidth obtained among the three PRMA is of the PRMA with rounded edges at the bottom. The bandwidth of this antenna is about $6.6 \mathrm{GHz}$. The value of VSWR is in the range from 1.08 to 1.989 , which is in compliance with 
theoretical value less than 2 . The more the value equal to 1 , less will be the power reflected from the antenna.

\section{ACKNOWLEDGMENT}

The authors would like to express their gratitude towards to Dr. Arvind Agrawal (Sameer, IIT Bombay) for allowing us to test the antenna at their testing center. The authors are also thankful to Thakur College of Engineering and Technology for providing with the required facilities for the project.

\section{REFERENCES}

1. K. P. Ray, "Design aspect of printed monopole antennas for ultra wide band application", Hindawi Publishing Corporation, International journal of antennas and propogation, Vol. 2008, article ID713858.

2. K.P. Ray, Y. Ranga, "Printed Rectangular Monopole Antennas," Antennas and Propagation Society International Symposium, IEEE Volume, No. 9, 2006, pp.1693 - 1696.

3. K. P. Ray, S. S. Thakur, and R. A. Deshmukh, "Broadbanding a printed rectangular monopole antenna", Applied Electromagnetics Conference (AEMC), SAMEER, Mumbai, India, pp. 1-4, 14-16 Dec. 2009.

4. K. P. Ray, Y. Ranga, P, Gabhale, "Printed square monopole antenna with semicircular base for ultra wide bandwidth", Electronics Letters, Vol. 43, No. 5, March 2007.

5. J. Liang, C. C. Chiau, X. Chen, C. G. Parini, "Printed circular disc monopole for ultra wide band applications", Electronics Letter, vol. 40, no 20, pp. 1246-1248, sep 2004.

6. M. J. Amman, "Square Planner Monopole Antenna", National conference on antennas and propogation, conference publication number 461, pp 37 -40, April 1999.

7. C.A. Balanis, "ANTENNA THEORY ANALYSIS AND DESIGN”, Second Edition, John Wiley \& Sons, INC., NY, 1997.

8. IE3D software, version 12.

9. Nader Behdad, "TUTORIAL ON IE3D”, EEL 6463: ANTENNAS II, spring 2007, University of Central Florida.

10. Leena Govekar \& Jyoti Kori, "BANDWIDTH INPROVEMENT OF PRINTED MONOPOLE ANTENNA", Advances in Communication and Computing Technologies (ICACACT), 2014 International Conference.

11. K.P. Ray \& Y Ranga, "PRINTED RECTANGULAR MONOPOLE ANTENNA", Antennas and Propagation Society International Symposium 2006, IEEE. 